March 13, $2010 \quad$ 10:34 B-936 b936-ch08

Chapter 8

\title{
Aircraft Observations of Tropical Cyclones
}

\author{
Sim D. Aberson and Joseph Cione \\ NOAA/AOML/Hurricane Research Division, \\ 4301 Rickenbacker Causeway, Miami, FL 33149 USA \\ sim.aberson@noaa.gov \\ joe.cione@noaa.gov \\ Chun-Chieh $\mathrm{Wu}$ \\ Department of Atmospheric Sciences, National Taiwan University, \\ No. 1, Sec. 4, Roosevelt Rd., Taipei 10673, Taiwan \\ cwu@typhoon.as.ntu.edu.tw \\ Michael M. Bell \\ Naval Postgraduate School and National Center for Atmospheric Research, \\ Department of Meteorology, 589 Dyer Road, Root Hall, \\ Monterey, CA 93943-5114 USA \\ mmbell@nps.edu \\ Jeffrey Halverson \\ University of Maryland-Baltimore County, Department of Geography \\ and Environmental Systems, 211-K Sondheim Hall, \\ 1000 Hilltop Circle, Baltimore, MD 21250 USA \\ jeffhalv@umbc.edu
}

Chris Fogarty

Environment Canada, National Laboratory for Marine and Coastal Meteorology, 45 Alderney Drive, Dartmouth, Nova Scotia B2Y 2N6, Canada

chris.fogarty@ec.gc.ca

Martin Weissmann

Deutsches Zentrum für Luft- und Raumfahrt, Institut für Physik der Atmosphäre,

Oberpfaffenhofen, Münchnerstr. 20,

D-82230 Wessling, Germany

martin.weissmann@dlr.de

Nine different types of aircraft are currently in use to observe tropical cyclones and their environments for operations and research. The following is a description of those aircraft, their instrumentation, and the field programs with which they have been involved. 


\section{Introduction}

Tropical cyclones (TCs) have been observed by aircraft since the first flight piloted by United States Army Air Force Lt. Col. Joseph P. Duckworth on 17 July, 1943 (Sumner, 1943). The United States military conducted the first dedicated research flight into a TC (Wexler, 1945; Wood, 1945), and a subsequent flight examined the upper troposphere of a 1947 Atlantic TC (Simpson, 1954). Regular aircraft reconnaissance of the tropics by the United States military to investigate whether TCs were developing, and their locations and intensities, soon began in both the Atlantic and Western Pacific basins. With the advent of satellite data, the importance of the airborne search for developing TCs decreased, and methods to locate and estimate the intensities of TCs were derived (Dvorak, 1975; Velden et al., 1998; Velden et al., 2006; Olander and Velden, 2007). However, the remotely sensed satellite location and intensity data remain less accurate than in situ aircraft measurements.

In addition to operational uses, aircraft have a long history in TC research. After the disastrous Atlantic hurricane season of 1954, the United States Weather Bureau created the National Hurricane Research Project (NHRP) to advance TC science and improve forecasts. NHRP soon pioneered quantitative observations with instrumented aircraft that shaped the modern understanding of tropical cyclones (Dorst, 2007).

The following is a discussion of the operational reconnaissance, surveillance and research aircraft that have participated in TC field programs since 1997 and the instrumentation available on them. This chapter is meant to summarize the types of observations available and their uses for research and operations, with broad information available in the references.

\section{NOAA P-3s}

In the mid-1970s, the United States National Oceanic and Atmospheric Administration
(NOAA) purchased two WP-3D (P-3) aircraft, modified United States Navy maritime reconnaissance aircraft that are versions of the civilian Lockheed Electra (Aberson et al., 2006). Proposed uses of the aircraft were observations of TC structure and dynamics, participation in TC modification experiments, and monitoring of TC formation, all with the goal of improving the $\mathrm{TC}$ forecast and warning process to limit damage and loss of life. Since then, the NOAA Aircraft Operations Center has maintained the P-3s to be among the premier meteorological research aircraft in the world.

When the P-3s were procured, only basics of TC structure were known (Shea and Gray, 1973). The hurricane was considered to be an approximately circular, axisymmetric vortex with nearly constant wind speeds extending to at least $400 \mathrm{hPa}$, and with deviations from axisymmetry considered to be gusts or largely due to vortex motion. The eyewall was thought to be vertically aligned up to $5-10 \mathrm{~km}$ above the surface, and funnel-shaped above. The eye was observed to have warm, moist air below an inversion, with clear, dry air above and ice clouds streaming inward near the top. Both the eyewall and rainbands were understood to have convergent airflow in low levels and outflow above. Rainbands were seen to move inward toward the eye and to cause intensification of eyewall convection. Numerical modeling of TCs was limited to idealized 2-dimensional studies due to a lack of adequate computer power and observations of the dynamic and thermodynamic fields in three dimensions, and only primitive techniques to assimilate the data into model initial conditions (Simpson and Riehl, 1981).

Partially as a result of observations from the $\mathrm{P}-3 \mathrm{~s}$, the description and understanding of TC behavior and structure were revolutionized. The NOAA P-3s have conducted missions into nearly $150 \mathrm{TCs}$ in the Atlantic and Eastern Pacific Oceans and near Australia. Data were obtained on the micro- to the synopticscale, and data analyses have led to many new insights about TC structure, dynamics, 
thermodynamics, and environmental interactions (Aberson et al., 2006).

Sophisticated instrumentation installed on and developed for the P-3s is unique among meteorological airborne platforms (see Jorgensen, 1984 for details of the original instrument installation). At the time of delivery, both P-3s measured flight-level temperature, pressure, and moisture and had a state-of-the-art inertial navigation system allowing for flightlevel wind vector calculations with $0.1-0.3 \mathrm{~ms}^{-1}$ accuracy; these data are transmitted in real-time at a rate of up to $0.1 \mathrm{~Hz}$, and are available in research mode at $1 \mathrm{~Hz}$. As electronic equipment and expendable probes became more accurate, smaller, faster and lighter, new instrumentation enhanced the potential to gather comprehensive TC research data sets. For example, P-3 instruments now include the airborne infrared radiation thermometer for remotely determining flight-level temperature in clear air (Barnes et al., 1991; Eastin et al., 2002), a stepped frequency microwave radiometer (SFMR) for estimating surface wind speed (Uhlhorn and Black, 2003), and Global Positioning System (GPS) navigation. Omega dropwindsondes (ODWsGovind, 1975) were first used in hurricane research in 1982 to provide wind and thermodynamic profiles, but did not report in cloudy regions nor provide wind measurements in the boundary layer. The GPS dropwindsonde (Hock and Franklin, 1999), first used in 1996, provided reliable wind and thermodynamic profiles in the TC eyewall and down to the surface for the first time, thus revolutionizing understanding of structures in the eyewall and boundary layer. Each aircraft also carries a workstation for airborne radar and dropwindsonde processing (Griffin et al., 1992).

Among the most advanced meteorological equipment on the P-3s are three digital radars. Two record the reflectivity signal: a $5.5-\mathrm{cm}(\mathrm{C}-$ band) wavelength (lower fuselage) radar extends below the fuselage and measures the horizontal distribution at all azimuth angles; a 3-cm (Xband) wavelength radar is in the tail (TA) and determines the reflectivity distribution along rays oriented either perpendicular to the aircraft track or at angles fore and aft within $25^{\circ}$ of the aircraft heading (Marks, 1985). A third radar with a $5.2 \mathrm{~cm}$ (C-band) wavelength is in the nose and scans horizontally back and forth looking forward; the pilots use it to avoid turbulent weather, and the data have not been recorded since 1987. Important additions to the radar systems first occurred in 1980 when a prototype Doppler signal processing system was added to the TA radar on one P-3 (Jorgensen et al., 1983) and again in 1988-1989 when refined radar data systems were installed on both aircraft (Marks, 2003). In 2006, an automated quality control and analysis system was applied to the TA radar data, and three-dimensional wind and reflectivity analyses are transmitted in near-realtime for use by operational forecasters and for testing data assimilation schemes in high-resolution regional hurricane model systems (Gamache et al., 1997; Gamache, 2005).

The P-3s are also equipped with Particle Measuring System probes (a Forward Scattering Spectrometer Probe and 2-Dimensional Optical Array Probes) mounted on the wing tips to distinguish between water and ice particles and estimate their sizes (Knollenberg, 1970; Black and Hallett, 1986; Gayet et al., 1993; Baumgardner and Korolev, 1997). Starting in 2008, one P-3 will have a full complement of particle imaging and non-imaging probes manufactured by Droplet Measurement Technologies (DMT). These probes include the Cloud Combination Probe, imaging particles from $0.025 \mathrm{~mm}-1.6 \mathrm{~mm}$ in diameter and (using forward scattering methods) measuring the diameters and number concentrations of cloud droplets in the range $0.003 \mathrm{~mm}-0.050 \mathrm{~mm}$. The DMT Precipitation Imaging probe images particles in the diameter range $0.100 \mathrm{~mm}^{-}$ $6.4 \mathrm{~mm}$. The DMT Cloud Aerosol Spectrometer is a non-imaging probe that measures particles from $0.00061 \mathrm{~mm}-0.005 \mathrm{~mm}$ (forward scattering) and $0.001-0.1 \mathrm{~mm}$ (backward scattering). These probes offer the capability to measure the 
size distribution and number concentrations of cloud particles over three decades of diameters with unparalleled accuracy. In addition, five field mills will allow for measurement of the threedimensional electric field vector. This combination of instruments will provide unprecedented observations of the role of water and ice microphysics and electrification on TC convection and structure.

In addition to obtaining atmospheric data, the P-3s have the ability to collect upper ocean observations. Each aircraft has 24 chutes in its fuselage for external ejection of airborne expendable bathythermographs (Boyd, 1987; Boyd and Linzell, 1993), current profilers (Sanford, 1971), and conductivity temperature depth profilers to measure ocean temperature, current, and salinity to a depth of $\sim 300 \mathrm{~m}$. A Scanning Radar Altimeter (SRA) measures surface directional wave spectra and rain rate, and transmits these data to operational forecasters in near real-time (Walsh et al., 2002; Wright et al., 2001). These provide important data at and near the ocean-atmosphere interface where the TC derives its energy, allowing for greater understanding and modeling of airsea interaction processes. All these instruments make the two P-3s the most advanced and comprehensive of all meteorological aircraft currently in use.

\section{NOAA G-IV}

In 1982, TC numerical modeling was in its infancy, and the most accurate track guidance available to forecasters was statistical. NOAA began to test the hypothesis that additional vertical wind and thermodynamic profiles in the TC environment (the "synoptic flow") would improve analyses and numerical model forecasts that provide operational guidance to human forecasters. The data obtained during P-3 research missions through 1996 helped to reduce errors in TC track forecasts from global and regional dynamical models significantly (Burpee et al., 1996).
The success of this research program led to the development of a new generation of dropwindsonde (Hock and Franklin, 1999) and the acquisition of a high-altitude jet aircraft, the Gulfstream-IV-SP (G-IV) as an operational platform for conducting synoptic surveillance missions. These operational flights, along with concurrent research into optimal targeting and sampling strategies and data assimilation, continue to improve National Centers for Environmental Prediction (NCEP) operational global model track forecasts significantly (Aberson, 2003). A complete G-IV flight and the required dropwindsondes cost about $\$ 40,000$, far less than the estimated average of $\$ 1$ million needed to evacuate just six miles of coastline for landfall (Aberson et al., 2006).

Because of limited flight time and dropwindsondes, optimal sampling strategies must be found. Aberson (2003) found that the most rapidly growing modes in the NCEP global model can be represented by regions of relatively large spread in the ensemble forecasting system $850-200 \mathrm{hPa}$ mean wind. In testing the efficacy of this sampling strategy, the important question is whether the removal of at least one-third of the dropwindsonde data that are in non-target regions has no negative impact on subsequent forecasts. More specifically, the question is whether targeting techniques define regions where mobile platforms such as aircraft should concentrate observations and other regions in which observations will have little or no impact on subsequent forecasts. When entire regions of large ensemble spread are sampled by regularly spaced observations, a statistically significant improvement to forecast tracks above that from assimilating far more data obtained symmetrically about the storm results.

Majumdar et al. (2006) and Reynolds et al. (2006) compared this and other techniques during the 2004 hurricane season. They concluded that singular vector targets were often located within an annulus around $500 \mathrm{~km}$ from the storm center, and/or at long distances from 
the storm in locations associated with features such as mid-latitude troughs. The targets suggested by the Ensemble Transform Kalman Filter were localized around the storm in either upstream or downstream locations where wind or temperature errors were correlated with those near the verification region. Evaluation of these techniques with observing system experiments using data from operational missions is ongoing.

In addition to synoptic surveillance, by 2008 , a TA Doppler radar and SFMR will be available on the G-IV to complement those instruments on the P-3s. The radar will measure reflectivity and three-dimensional wind field similarly to the P-3 TA radars, but from a much higher altitude. This may allow for three-dimensional wind measurements in the TC cirrus outflow. The SFMR will measure surface wind speed and rain rate below the aircraft in a similar manner to the instruments available on the P-3 and C-130 aircraft, but at a lower resolution and with a larger footprint due to the aircraft altitude and speed. The G-IV will have the ability to transmit these data to the Global Telecommunications System (GTS) in real time.

\section{Taiwanese ASTRA SPX}

At least partially due to the success of the NOAA G-IV, the Dropwindsonde Observations for Typhoon Surveillance near the Taiwan Region (DOTSTAR) began in 2003 (Wu et al., 2005, 2007b). Data from dropwindsondes released from the ASTRA aircraft have substantially improved track model forecasts (Wu et al., 2007b). However, the average improvement to typhoon track prediction in the Geophysical Fluid Dynamics Laboratory (GFDL) hurricane model was insignificant, likely due to the dropwindsonde signal being swamped by the synthetic vortex data used during the initialization. As a result, Chou and Wu (2008) devised an alternative technique to combine dropwindsonde and synthetic data in a mesoscale model in order to further boost the effectiveness of dropwindsonde data with the implanted storm vortex.
An additional targeting technique, the Adjoint-Derived Sensitivity Steering Vector (ADSSV), has been devised and tested during these missions (Wu et al., 2007a). By appropriately defining a response function to represent the deep-layer-mean $(850-300 \mathrm{hPa})$ steering flow around the TC at the verifying time, sensitive locations at the observing time are clearly shown. The ADSSV relates these sensitive areas to the steering flow at the verifying time. The ADSSV direction and magnitude at a given location indicates the change in the steering flow due to a perturbation in the initial conditions at that location and the extent of the sensitivity, respectively. This adjoint sensitivity can be used to identify important regions and dynamical features affecting the TC track and is helpful in defining target regions for surveillance. The ADSSV has been used to design missions for DOTSTAR as well as for Atlantic hurricanes.

\section{United States Air Force WC130-Js}

The United States Air Force Reserve 53rd Weather Reconnaissance Squadron operates a fleet of ten Lockheed-Martin C-130-J aircraft that are mostly used for operational hurricane fixing (finding of the center location and storm intensity) in the Atlantic and Eastern and Central Pacific basins when TCs threaten land. Like the NOAA P-3s, these aircraft measure and transmit flight-level wind, pressure, temperature, and moisture data, as well as surface wind speed measurements from SFMR and data from dropwindsondes. As the vast majority of operational flights are conducted by these aircraft, they are the workhorses of aircraft reconnaissance and provide the most fixes yearly to operational centers; the data are also frequently used for research. In addition to these tasks, these aircraft also participate in synoptic surveillance missions to augment coverage from the G-IV, and in research experiments by providing air deployment of large platforms such as buoys and 
floats necessary for ocean observations (Black et al., 2007).

\section{Naval Research Laboratory P-3}

The Naval Research Laboratory (NRL) NP3D "Orion" aircraft is similar in design to the NOAA P-3s, but with a different instrumentation suite. It is maintained and deployed by the NRL Military Support Division and the Scientific Development Squadron-1 (VXS-1) "Warlocks" (formerly Flight Support Detachment) for a variety of military and scientific missions. After the decommission of the National Center for Atmospheric Research (NCAR) Electra aircraft in 2001, an agreement between NRL, the National Science Foundation, and NCAR to use this aircraft as the new platform for the Electra Doppler Radar (ELDORA) was reached. An Airborne Vertical Atmospheric Profiling System (AVAPS) system was installed in 2005 to allow for dropwindsonde processing (Hock and Franklin, 1999), augmenting the radar and in situ measurements obtained from the inertial navigation system.

ELDORA is a dual beam, X-band $(3.2 \mathrm{~cm})$ meteorological research TA radar developed jointly by NCAR and the Centre de Recherches en Physique de L'Environnement Terrestre et Planetaire (Hildebrand et al., 1994), first deployed in 1993 (Hildebrand et al., 1996). It has two flat-plate, slotted waveguide antennas with oval beamwidths of $1.8^{\circ} \times 2.0^{\circ}$ that spin about the longitudinal axis of the aircraft. The antenna rotodome is a radome that rotates with the antennas. One antenna points slightly fore of the aircraft and the other slightly aft. As the P-3 flies, these two radars trace conical helixes through the atmosphere, providing three-dimensional precipitation and kinematic structure at resolutions finer than $400 \mathrm{~m}$. This is similar to the NOAA TA radars using the Fore/Aft Scanning Technique (F/AST), but with $\sim 4$ times the spatial resolution due to the dual-transmitters and a higher antenna rotation rate (up to 24 revolutions per minute). Though the high rotation rate improves the alongtrack resolution, it limits the number of independent samples in a radar volume necessary for accurate Doppler radial velocity measurements (i.e., the time for each beam to obtain a significant sample is shorter). The velocity statistics are improved with a complex waveform pulse within which four separate frequency subpulses are coded, enabling the received signals to be processed individually. A dual pulse repetition frequency technique increases the maximum unambiguous velocity to greater than $60 \mathrm{~ms}-1$ while maintaining a $75 \mathrm{~km}$ unambiguous range, a highly desirable attribute in highwind regimes (Wakimoto et al., 1996; Wakimoto et al., 2004).

The first use of the NRL P-3 for TC observations was in 2005, during the Hurricane Rainband and Intensity Change Experiment (RAINEX-Houze et al., 2006). In cooperation with the three NOAA aircraft, the P-3 investigated hurricane intensity changes associated with eyewall-rainband interactions. Nine missions were flown into Hurricanes Katrina, Ophelia, and Rita, documenting many different stages of the TC life cycle and a variety of rainband configurations. One of the unique aspects of this project was the coordination among the multiple aircraft, including transmitted composite LF radar images from the NOAA P-3s to the NRL P-3 for navigation assistance. The high level of detail in TC precipitation and kinematic structure is a significant observational advancement resulting from the use of ELDORA in RAINEX.

This platform's second deployment to study TCs took place in the summer of 2008 as part of the THORPEX Pacific Area Regional Campaign (T-PARC) and Tropical Cyclone Structure 2008 (TCS-08) field programs. A Doppler wind lidar was added to the instrumentation to provide wind profiles in clear air below the aircraft, and the missions focused on the genesis, structural changes, and extratropical transition of TCs, extending the life cycle observed by the NRL P-3 and ELDORA. 

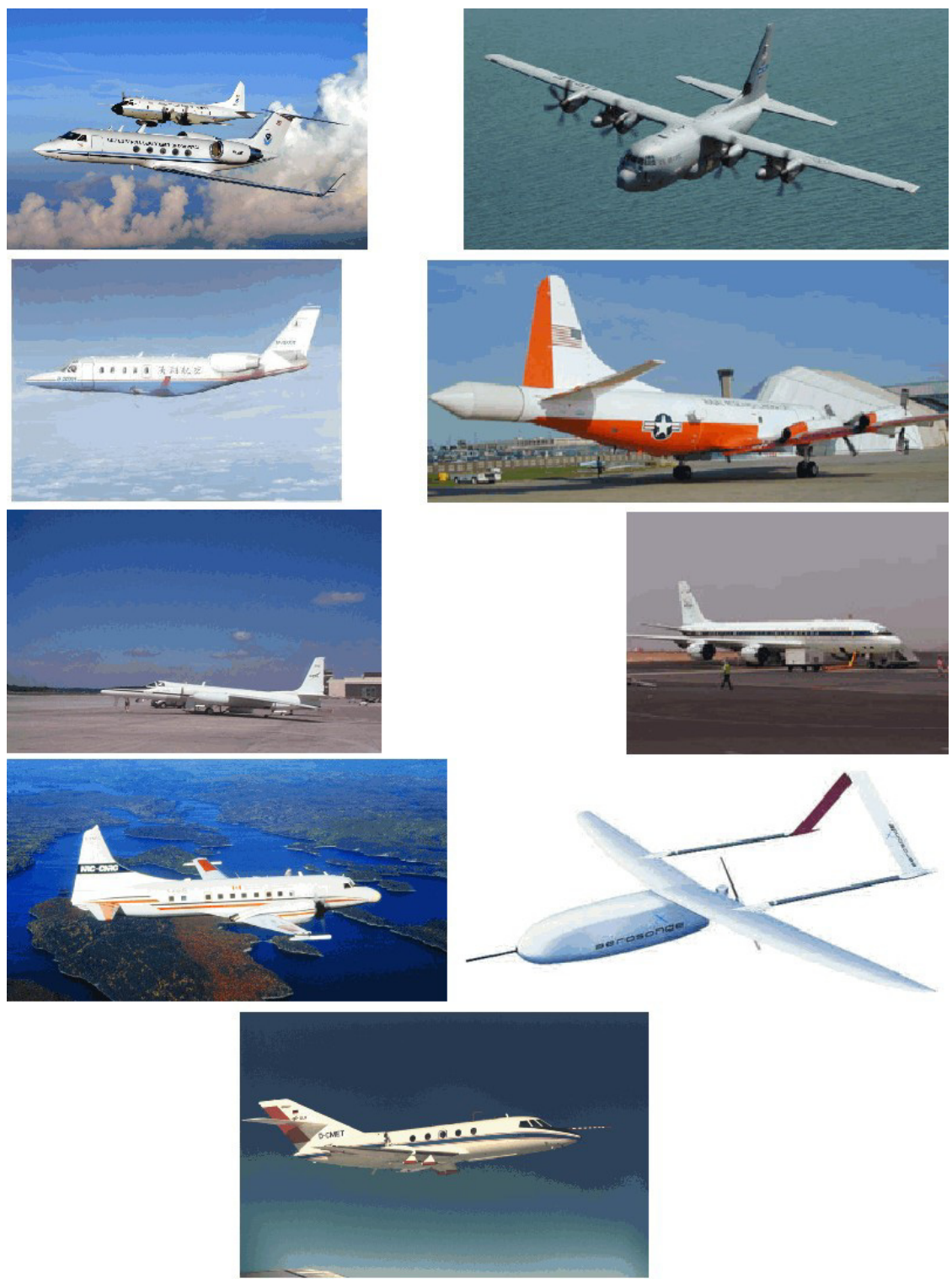

Figure 1. Aircraft described in this chapter. Clockwise from top left: NOAA P-3 (top) and G-IV (bottom), AF C-130, NRL P-3, NASA DC-8, Aerosonde, DLR Falcon, Canadian Convair, NASA ER-2, and Taiwanese ASTRA.

\section{NASA DC-8 and ER-2}

For more than a decade, the National Aeronautics and Space Administration (NASA) Science Mission Directorate (SMD) has utilized high-altitude research aircraft to conduct scientific investigations of $\mathrm{TC}$ genesis, intensity change and landfall impacts. The principal airborne platforms include the McDonald Douglas DC-8 and Lockheed Martin Earth Resources-2 (ER-2).

NASA began flying sorties into TCs in Tropical Cyclone Oliver in January, 1993, in the Coral Sea during the Tropical Oceans/ 
Global Atmosphere Program. Since then, NASA has conducted four major hurricane research field programs. These include: the Convection and Moisture Experiments (CAMEX-3 and CAMEX-4) of 1998 and 2001 (Kakar et al., 2006); the Tropical Cloud Systems and Processes experiment (TCSP) of 2005 (Halverson et al., 2007); and the NASA African Monsoon Multidisciplinary Activities (NAMMA) of 2006. CAMEX was designed to intensively study TC structure and intensity change. TCSP was focused on tropical cyclogenesis, but also sampled the unusually intense, earlyseason Atlantic Hurricanes Dennis and Emily. NAMMA sought to investigate the metamorphosis of African easterly waves into named TCs as they emerged off the coast of western Africa.

The field experiments were jointly planned and implemented in coordination with the NOAA P-3s and G-IV aircraft. The advantages of the combined effort include the complementary nature of scientific objectives contained in both the NASA and NOAA research plans. The main advantage is that the NOAA P-3 aircraft fly low, and the NASA aircraft fly high, enabling investigation of the complete TC vertical structure from 70,000 feet down through the oceanic mixed layer. Coordinated surveys involving multiple aircraft require diligent planning, real-time mission monitoring and reliable radio contact to keep as many as five aircraft arranged in a moving, vertical stack. Flights nominally last $6-8$ hours with the DC- 8 sampling the storm between 30,000-40,000 feet and the ER-2 operating entirely above the storm close to 70,000 feet.

The aircraft payloads consist of a diverse suite of in situ and remote sensing instruments varying with each field campaign. They test new technologies, some of which may undergo transition to satellite platforms. From its very high vantage point, the ER-2 can serve as a "virtual satellite" to target observations to the particular scientific objective. The DC- 8 spends most of its time within the $\mathrm{TC}$ core and is best suited to sample electrical fields, cloud and precipitation particles, and the three-dimensional water vapor structure. Missions may be timed to coincide with one or more NASA satellite overpasses in order to provide crucial calibration/validation information.

Several classes of instruments are common to most missions on the DC-8. Instruments designed to measure the in situ temperature, moisture, pressure, and winds comprise the Meteorological Measurement System, and a 4-channel AVAPS (Hock and Franklin, 1999) allows for GPS dropwindsonde processing. One or more hygrometers such as the Diode Laser Hygrometer (Heymsfield et al., 1998) and Jet Propulsion Laboratory Laser Hygrometer (May, 1998) provide precise measurements of water vapor, with high accuracy at very low ambient humidity. The Lidar Atmospheric Sensing Experiment (Miloshevich et al., 2004) provides high resolution, vertical profiles of water vapor mixing ratio and aerosol scatter. A series of nadir-viewing Doppler radars (Airborne Mapping Radar [Durden et al., 2003]; Precipitation Radar [Im et al., 2002] and the Dual-Frequency Airborne Precipitation Radar [APR-2]) provide fine-scale vertical precipitation (reflectivity) structure, particularly within stratiform rain regions, as well as radial wind measurements, and have served as prototypes of instruments flown on the Tropical Rainfall Measurement Mission (Simpson et al., 1988; Kummerow et al., 1998) and the planned Global Precipitation Mission (Smith et al., 2002). The DC-8 also typically hosts a suite of cloud microphysics probes; these include the Cloud Particle Imager (Heymsfield and Miloshevich, 2003) to measure ice particle size, Counterflow Virtual Impactor (Twohy et al., 2003) to measure cloud liquid water content, and the Cloud and Aerosol Particle Characterization (McFarquhar and Heymsfield, 1997) system of probes that measures the particle size distribution from $30 \mu \mathrm{m}$ to above $1 \mathrm{~mm}$ in $30-\mu \mathrm{m}$ increments.

Instrument payloads on the ER-2 are geared toward remote sensing and retrieval of 
atmospheric vertical profiles. The Advanced Microwave Precipitation Radiometer (Spencer et al., 1994) uses a combination of passive microwave frequencies at high spatial and temporal resolution to map instantaneous rain rate. The ER-2 Doppler Radar (Heymsfield et al., 1996) uses both nadir and forwarddirected active beams to detect fine-scale precipitation structure and radial motions within convective and stratiform precipitation. Electrical field mill measurements are provided by the Lightning Imaging Package. The High Altitude Monolithic Microwave Integrated Circuit Sounding Radiometer (Lambrigtsen and Riley, 2002) obtains temperature and humidity profiles, liquid water profiles and rain rate. Vertical temperature profiles, tropopause height and high-altitude lapse rate are also retrieved using the Microwave Temperature Profiler (Denning et al., 1989). The Moderate Resolution Imaging Spectroradiometer Airborne Simulator (Roskovensky et al., 2004) provides multispectral visible and infrared cloudtop imagery at $50 \mathrm{~m}$ horizontal resolution. Recent additions to the ER-2 payload suite include the fully autonomous ER-2 High Altitude Dropsonde and the Cloud Radar System (Li et al., 2004; Halverson et al., 2006) that provides high sensitivity radar reflectivity, Doppler velocity and derived measurements of cloud ice.

Many of these instruments are being specifically adapted for use on the Global Hawk Unmanned Airborne System (UAS) to provide long-duration, high-altitude missions during the NASA Hurricane and Severe Storm Sentinel research initiative. The goal is to observe tropical cyclogenesis and intensification from tropical storm to hurricane during an extended time period, operating in a surveillance rather than a reconnaissance mode.

\section{Canadian Convair-580}

The first research aircraft mission into a hurricane (Michael) undergoing extratropical transition was arranged by the Meteorological
Service of Canada using the Canadian National Research Council Convair-580 aircraft on 19 October, 2000. A comprehensive description of the aircraft specifications and of experiences during the Michael flight is provided in Wolde et al., (2001). At the time, Michael was near maximum intensity and undergoing rapid transition to an extratropical storm. Since this was the first time the aircraft was being flown into a storm of that nature, the pilots chose not to fly directly through the storm center which contained vigorous convection, lightning and very strong wind in the lower levels near the boundary layer as measured by dropwindsondes and airborne conventional radar (Abraham et al., 2004). The Convair-580 aircraft was equipped with cloud microphysical probes which collected information on the ice and cloud liquid water concentrations within the storm. Ice water concentrations on the western side of the storm in the stratiform precipitation region were very high, and more characteristic of concentrations seen in the center of continental cumulonimbus clouds. Data from the mission led to improved initialization techniques for numerical models (Fogarty et al., 2007).

Other missions were conducted into Tropical Storms Karen (2001) and Isabel (2003), and Hurricane Juan (2003). The flight in Hurricane Juan south of Nova Scotia provided an unprecedented look at a strong hurricane making landfall in Canada with destructive effects (Fogarty et al., 2006).

\section{DLR Falcon}

In 2008, the Falcon 20 aircraft of the Deutsches Zentrum für Luft-und Raumfahrt (DLR) in Oberpfaffenhofen, Germany was deployed to the West-Pacific for typhoon research as part of T-PARC. The main objectives were targeted observations to improve typhoon forecasts and the investigation of extra-tropical transition of tropical cyclones and downstream impact in the mid-latitudes. In coordination with the NRL 
P-3, the USAF WC-130 and DOTSTAR unique typhoon observations from genesis through recurvature and extra-tropical transition, with simultaneous observations of the typhoon core and environment and sensitive areas related to the midlatitude flow or the subtropical high often highlighted by singular vector sensitivity calculations, were obtained. Typhoons Sinlaku and Jangmi were observed for 13 and 9 days, respectively. One particular focus of the data analysis will be to evaluate which observational strategies are most effective for typhoon forecasting and observations in which regions have the highest potential for forecast improvements.

Options for instrumentation including dropwindsondes, air chemistry probes, aerosol and particle probes and various lidars. For T-PARC it was configured with a dropwindsonde system, a scanning coherent wind lidar (Weissmann et al., 2005) and a four-wavelength differential absorption lidar for water vapour that includes a high spectral-resolution channel to measure aerosol extinction. The individual observations are volume averages and thus seen as more useful (representative) information for assimilation in numerical models than point observations like dropwindsondes. This was pointed out by Weissmann and Cardinali (2007) using wind lidar observations during the Atlantic THORPEX Regional Campaign (A-TReC) and will be an important subject of future T-PARC research.

One restriction of lidars is that they can not penetrate optically thick clouds; if clouds are at the flight level, the aircraft must reduce its altitude to get observations. Conversely, in clear air, the wind lidar must have sufficient aerosols to determine winds or data gaps occur. The optimal mix of lidar and other observations (i.e., dropwindsondes) therefore requires further research.

\section{UASs}

The interaction between the ocean and the hurricane is important, complex, and not well handled in current observing systems and models. Specifically, the hurricane depends on the ocean to supply the heat necessary to form and maintain the storm. The detailed process by which a storm obtains heat from the ocean and ultimately converts it into kinetic energy (i.e., strong winds) is complex and not well understood due to the limited availability of detailed observations within the storm near the air-sea interface. To dramatically improve understanding of this rarely observed region, these low-level observations must be obtained. Unmanned aerial systems (UAS) designed to penetrate and sample the violent low-level hurricane environment can fill this critical data void.

Two groups, a NOAA/NASA team and one based in Taiwan, have used the Aerosonde (Holland et al., 2001) to this end. Aerosonde missions are conducted in completely robotic mode with the aircraft monitored by a ground controller. The Aerosondes used in TC missions have measured temperature, humidity, pressure, and wind speed and direction, but they have the ability to use interchangeable instrument payloads allowing for other measurements. During a mission into hurricane Noel (2007), NOAA/NASA set endurance $(17.5 \mathrm{~h})$ and minimum altitude $(82 \mathrm{~m})$ records for a UAS in a TC environment. During the missions into Typhoon Longwang (2005), four passes through the eyewall were completed, and maximum 10-min (1-min) wind speed of $58.6 \mathrm{~ms}^{-1}$ $\left(62 \mathrm{~m} \mathrm{~s}^{-1}\right)$ were measured (Lin and Lee, 2008). The aircraft is therefore able to complete long missions into severe tropical cyclones globally.

The UAS data obtained during recent missions conducted by the NOAA/NASA team (Ophelia in 2005 and Noel in 2007) have proved to be very useful. In both cases, near-surface observations were reported to the National Hurricane Center in real-time to be used during operational warning. The UAS found the highest wind speeds in both storms despite the presence of manned aircraft at the same time. Analysis of the data from these missions is proceeding, 
and further missions with various UAS platforms are planned. A major goal is to transmit the data operationally for assimilation into highresolution tropical cyclone model systems and to greatly expand the amount of data available at the undersampled air-sea interface in the TC core.

\section{Conclusions}

Sampling of TC cores is currently performed routinely only in the Atlantic basin, though reconnaissance in the eastern and central Pacific is occasionally tasked. In all other TC-prone ocean basins, in situ information is rarely obtained. Though satellites are certainly capable of some measurements similar to those obtained by aircraft, the ability of satellites to obtain the necessary data both accurately and with the necessary spatial and temporal resolution in all TC basins remains in doubt. Aircraft remain the sole platform by which data can be obtained for operations, and are a testing ground for new instruments that may be put into orbit on future satellite systems, as well as for calibration and validation of current and future satellite observing systems, not only for operational purposes, but to improve TC monitoring for the assessment of climatic changes. These data are also required for the development of high-resolution model systems, especially nextgenerational data assimilation systems, that are necessary to provide accurate forecasts of TC intensity, rainfall and structure.

\section{References}

Aberson, S. D., M. L. Black, R. A. Black, R. W. Burpee, J. J. Cione, C. W. Landsea, and F. D. Marks, Jr., 2006: Thirty years of tropical cyclone research with the NOAA P-3 aircraft. Bull. Amer. Met. Soc., 87, 1039-1055.

Aberson, S. D., 2003: Targeted observations to improve operational tropical cyclone track forecast guidance. Mon. Wea. Rev., 131, 16131628.
Abraham, J., W. Strapp, C. Fogarty, and M. Wolde, 2004: Extratropical transition of Hurricane Michael: An aircraft investigation. Bull. Amer. Meteor. Soc., 85, 323-339.

Barnes, G. M., J. F. Gamache, M. A. LeMone, and G. J. Stossmeister, 1991: A convective cell in a hurricane rainband. Mon. Wea. Rev., 119, 776794.

Baumgardner, D. and A. Korolev, 1997: Air speed corrections for optical array probe sample volumes. J. Atmos. Ocean. Technol., 14, 12241229.

Black, P. G., E. A. D'Asaro, W. M. Drennan, J. R. French, P. P. Niiler, T. B. Sanford, E. J. Terrill, E. J. Walsh, and J. A. Zhang, 2007: Air-sea exchange in hurricanes: Synthesis of observations from the coupled boundary layer air-sea transfer experiment. Bull. Amer. Met. Soc., 88, 357-374.

Black, R. A. and J. Hallett, 1986: Observations of the distribution of ice in hurricanes. J. Atmos. Sci., 43, 802-822.

Boyd, J. D., 1987: Improved depth and temperature conversion equations for Sippican AXBTs. J. Atmos. Ocean. Technol., 4, 545-551.

Boyd, J. D. and R. S. Linzell, 1993: Evaluation of the Sparton tight-tolerance AXBTs. J. Atmos. Ocean. Technol., 10, 892-899.

Burpee, R. W., J. L. Franklin, S. J. Lord, R. E. Tuleya, and S. D. Aberson, 1996: The impact of Omega dropwindsondes on operational hurricane track forecast models. Bull. Amer. Met. Soc., 77, 925-933.

Chou, K.-H. and C.-C. Wu, 2008: Development of the typhoon initialization in a mesoscale model combination of the bogused vortex and the dropwindsonde data in DOTSTAR. Mon. Wea. Rev., in press.

Denning, R. F., S. L. Guidero, G. S. Parks, and B. L. Gary, 1989: Instrument description of the airborne microwave temperature profiler. J. Geophys. Res., 94, 16757-16765.

Dorst, N. M., 2007: The National Hurricane Research Project: 50 years of research, rough rides, and name changes. Bull. Amer. Met. Soc., 88, 1566-1588.

Durden, S. L., E. Im, Z. S. Haddad, and L. Li, 2003: Comparison of TRMM precipitation radar and airborne radar data. J. Appl. Meteor., 42, 769-774.

Dvorak, V. F., 1975: Tropical cyclone intensity analysis and forecasting from satellite imagery. Mon. Wea. Rev., 103, 420-430.

Eastin, M. D., P. G. Black, and W. M. Gray, 2002: Flight-level thermodynamic instrument wetting 
errors in hurricanes: Part I: Observations. Mon. Wea. Rev., 130, 825-841.

Fogarty, C. T., R. J. Greatbatch, and H. Ritchie, 2007: The use of a vortex insertion technique to simulate the extratropical transition of Hurricane Michael (2000). Wea. Forecasting, 22, 480-500.

Fogarty, C. T., R. J. Greatbatch, and H. Ritchie, 2006: The role of anomalously warm sea surface temperatures on the intensity of Hurricane Juan (2003) during its approach to Nova Scotia. Mon. Wea. Rev., 134, 1484-1504.

Gamache, J. F., 1997: Evaluation of a fully-three dimensional variational Doppler analysis technique. Preprints, 28th Conference on Radar Meteorology, Austin, TX, Amer. Meteor. Soc., pp. $422-423$.

Gamache, J. F., 2005: Final Report on JHT Project entitled: Real-Time Dissemination of Hurricane Wind Fields Determined from Airborne Doppler Radar Data. Available at http://www.nhc.noaa.gov/jht/2003-2005reports/ DOPLRgamache_JHTfinalreport.pdf

Gayet, J. F., P. R. A. Brown, and F. Albers, 1993: A comparison of in-cloud measurements obtained from six PMS 2D-C probes. J. Atmos. Ocean. Technol., 10, 180-194.

Govind, P. K., 1975: Dropwindsonde instrumentation for weather reconnaissance aircraft. J. Appl. Meteor., 14, 1512-1520.

Griffin, J. S., R. W. Burpee, F. D. Marks, and J. L. Franklin, 1992: Real-time airborne analysis of aircraft data supporting operational hurricane forecasting. Wea. Forecasting, $\mathbf{7}$, 480-490.

Halverson, J. and co-authors, 2007: NASA's tropical cloud systems and processes experiment. Bull. Amer. Met. Soc., 88, 867-882.

Halverson, J. B., J. Simpson, G. Heymsfield, H. Pierce, T. Hock, L. Ritchie, 2006: Warm core structure of Hurricane Erin diagnosed from high altitude dropsondes during CAMEX-4. J. Atmos. Sci., 63, 309-324.

Heymsfield, A. J., L. M. Miloshevich, G. Sachse, C. Twohy, and S. Oltmans, 1998: Upper tropospheric relative humidity observations and implications for cirrus ice nucleation. Geophys. Res. Lett., 25, 1343-1346.

Heymsfield, L. M. and L. M. Miloshevich, 2003: Parameterizations for the cross-sectional area and extinction of cirrus and stratiform ice cloud particles. J. Atmos. Sci., 60, 936-956.

Heymsfield, G. M. and co-authors, 1996: The EDOP radar system on the high-altitude NASA
ER-2 aircraft. J. Atmos. Ocean. Technol., 13, 795-809.

Hildebrand, P. H., C. L. Frush, and C. Walther, 1994: Design of the ELDORA/ASTRAIA airborne Doppler weather radar: Goals, design, and first field test. Proc. IEEE, 82, 1873-1890.

Hildebrand, P. H., W.-C. Lee, C. A. Walther, C. Frush, M. Randall, E. Loew, R. Neitzel, R. Parsons, J. Testud, F. Baudin, and A. LeCornec, 1996: The ELDORA/ASTRAIA airborne Doppler weather radar: High resolution observations from TOGA COARE. Bull. Amer. Met. Soc., 77, 213-232.

Hock, T. F. and J. L. Franklin, 1999: The NCAR GPS dropwindsonde. Bull. Amer. Meteor. Soc., 80, 407-420.

Holland, G. J., P. J. Webster, J. A. Curry, G. Tyrell, D. Gauntlett, G. Brett, J. Becker, R. Hoag, and W. Vaglienti, 2001: The Aerosonde robotic aircraft: A new paradigm for environmental observations. Bull. Amer. Met. Soc., 82, 889-901.

Houze, R. A., S. S. Chen, B. F. Smull, W.-C. Lee, and M. M. Bell, 2007: Hurricane intensity change and eyewall replacement. Science, 315, 12351239.

Im, E. and co-authors, 2002: Second-Generation Precipitation Radar (PR-2). Final Rep. JPL D-22997, NASA Earth Science Instrument Incubator Program, Jet Propulsion Laboratory, California Institute of Technology, Pasadena, CA, 164 pp.

Jorgensen, D. P., 1984: Mesoscale and convectivescale characteristics of mature hurricanes. Part I: General observations by research aircraft. J. Atmos. Sci., 41, 1267-1285.

- P. H. Hildebrand, and C. L. Frush, 1983: Feasibility test of an airborne pulse-Doppler meteorological radar. J. Appl. Meteor., 22, 744-757.

Kakar, R., M. Goodman, R. Hood, and A. Guillory, 2006: Overview of the Convection and Moisture Experiment (CAMEX). J. Atmos. Sci., 63, 5-18.

Knollenberg, R. G., 1970: The optical array: An alternative to scattering or extinction for airborne particle size determination. J. Appl. Meteor., 9, 86-103.

Kummerow, C., W. Barnes, T. Kozu, J. Shiue, and J. Simpson, 1998: The Tropical Rainfall Measuring Mission (TRMM) sensor package. J. Atmos. Ocean. Technol., 15, 809-817.

Lambrigtsen, B. H. and A. L. Riley, 2002: Microwave scattering observed in convective cells during CAMEX-4. Preprints, 22d Conf. on Hurricanes 
and Tropical Meteorology, San Diego, CA, Amer. Meteor. Soc., 515-516.

Li, L., G. M. Heymsfield, P. E. Racette, T. Lin, and E. Zenker, 2004: A 94-GHz cloud radar system on a NASA high-altitude ER-2 aircraft. J. Atmos. Ocean. Technol., 21, 1378-1388.

Lin, P.-H. and C.-S. Lee, 2008: The eyewallpenetration reconnaissance observation of Typhoon Longwang (2005) with unmanned aerial vehicle, Aerosonde. J. Atmos. Ocean. Technol., 25, 15-25.

Majumdar, S. J., S. D. Aberson, C. H. Bishop, R. Buizza, M. S. Peng, and C. A. Reynolds, 2006: A comparison of adaptive observing guidance for Atlantic tropical cyclones. Mon. Wea. Rev., 134, 2354-2372.

Marks, F. D., Jr., 1985: Evolution of the structure of precipitation in Hurricane Allen (1980). Mon. Wea. Rev., 113, 909-930.

Marks, F. D., 2003: State of the science: Radar view of tropical cyclones. Radar and Atmospheric Science: A Collection of Essays in Honor of David Atlas, edited by R. M Wakimoto and R. C. Srivastava, Meteorological Monographs, 52, AMS, Boston, MA, 33-74.

May, R. D., 1998: Open-path, near-infrared tunable diode laser spectrometer for atmospheric measurements of H2O. J. Geophys. Res., 103, $19161-19172$

McFarquhar, G. M. and A. J. Heymsfield, 1997: Parameterization of tropical cirrus ice crystal size distributions and implications for radiative transfer: Results from CEPEX. J. Atmos. Sci., 54, 2187-2200.

Miloshevich, L. M., A. Paukkunen, H. Vömel, and S. J. Oltmans, 2004: Development and validation of a time-lag correction for Vaisala radiosonde humidity measurement. J. Atmos. Ocean. Technol., 21, 1305-1327.

Olander, T. L. and C. S. Velden, 2007: The advanced Dvorak technique: Continued development of an objective scheme to estimate tropical cyclone intensity using geostationary infrared satellite imagery. Wea. Forecasting, 22, 287-298.

Reynolds, C. A., M. S. Peng, S. J. Majumdar, S. D. Aberson, C. H. Bishop, and R. Buizza, 2007: Interpretation of adaptive observing guidance for Atlantic tropical cyclones. Mon. Wea. Rev., 135, 4006-4029.

Roskovensky, J., K. N. Liou, T. J. Garrett, and D. Baumgardner, 2004: Simultaneous retrieval of aerosol and thin cirrus optical depths using MODIS airborne simulator data during
CRYSTAL-FACE and CLAMS. Geophys. Res. Lett., 31, L18110.

Sanford, T. B., 1971: Motionally-induced electric and magnetic fields in the sea. J. Geophys. Res., 76, 3476-3492.

Simpson, J., R. F. Adler, and G. R. North, 1988: A proposed Tropical Rainfall Measuring Mission (TRMM) satellite. Bull. Amer. Meteor. Soc., 69, 278-295.

Simpson, R. H., 1954: Hurricanes. Scientific American, 109, 22-37.

Simpson, R. H. and H. Riehl, 1981: The hurricane and its impact. Louisiana State University Press, Baton Rouge, LA, 398 pp.

Smith, E. A., A. Mehta, and J. M. Shepherd, 2002: Description of Global Precipitation Measurement (GPM) Mission. NASA/Goddard Space Flight Center, GPM Report Series 6, Tech Memo., $25 \mathrm{pp}$.

Spencer, R. W., R. E. Hood, F. J. Lafontaine, E. A. Smith, R. Platt, J. Galliano, V. L. Griffin, and E. Lobl, 1994: High resolution imaging of rain systems with the Advanced Microwave Precipitation Radiometer. J. Atmos. Ocean. Technol., 11, 849-857.

Sumner, H. C., 1943: North Atlantic hurricanes and tropical disturbances of 1943. Mon. Wea. Rev., 71, 179-183.

Twohy, C. H., J. W. Strapp, and M. Wendisch, 2003: Performance of a counterflow virtual impactor in the NASA Icing Research Tunnel. J. Atmos. Ocean. Technol., 20, 781-790.

Uhlhorn, E. W. and P. G. Black, 2003: Verification of remotely sensed sea surface winds in hurricanes. J. Atmos. Ocean. Technol., 20, 99-116.

Velden, C. S., T. L. Olander, and R. M. Zehr, 1998: Development of an objective scheme to estimate tropical cyclone intensity from digital geostationary satellite infrared imagery. Wea. Forecasting, 13, 172-186.

, and co-authors, 2006: The Dvorak tropical cyclone intensity estimation technique: A satellite-based method that has endured for over 30 years. Bull. Amer. Met. Soc., 87, $1195-1210$

Wakimoto, R. M., W.-C. Lee, H. B. Bluestein, C.-H. Liu, P. H. Hildebrand, 1996: ELDORA observations during VORTEX 95. Bull. Amer. Met. Soc., 77, 2949-2950.

Wakimoto, R. M., H. Cai, and H. V. Murphey. 2004: The Superior, Nebraska, Supercell During BAMEX. Bull. Amer. Met. Soc., 85, 1095-1106.

Walsh, E. J., C. W. Wright, D. Vandemark, W. B. Krabill, A. W. Garcia, S. H. Houston, 
S. T. Murillo, M. D. Powell, P. G. Black, and F. D. Marks Jr., 2002: Hurricane directional wave spectrum spatial variation at landfall. J. Phys. Ocean., 32, 1667-1684.

Weissmann, M. and C. Cardinali, 2007: The impact of airborne Doppler lidar measurements on ECMWF forecasts. Quart. J. Roy. Meteor. Soc., 133, 107-116.

Weissmann, M., R. Busen, A. Dörnbrack, S. Rahm, and O. Reitebuch, 2005: Targeted observations with an airborne wind lidar. J. Atmos. Ocean. Technol., 22, 1706-1719.

Wexler, H., 1945: The structure of the September, 1944, hurricane when off Cape Henry, Virginia. Bull. Amer. Meteor. Soc., 26, 156-159.

Wolde, M., D. Marcotte, J. Jordan, J. Aitken, J. Abraham, and J.W. Strapp, 2001: The first Canadian experience with research flight operations in hurricane extratropical transition. Canadian Aeronautics and Space Journal, 47(3), 179-189.

Wood, F. B., 1945: A flight into the September, 1944, hurricane off Cape Henry, Virginia. Bull. Amer. Meteor. Soc., 26, 153-156.
Wright, C. W., E. J. Walsh, D. Vandemark, W. B. Krabill, A. W. Garcia, S. H. Houston, M. D. Powell, P. G. Black, and F. D. Marks, 2001: Hurricane directional wave spectrum spatial variation in the open ocean. J. Phys. Ocean., 31, $2472-2488$.

Wu, C.-C., J.-H. Chen, P.-H. Lin, and K.-H. Chou, 2007a: Targeted observations of tropical cyclone movement based on the adjoint-derived sensitivity steering vector. J. Atmos. Sci., 64, 26112626.

Wu, C.-C., K.-H. Chou, P.-H. Lin, S. D. Aberson, M. S. Peng, and T. Nakazawa, 2007b: The impact of dropwindsonde data on typhoon track forecasts in DOTSTAR. Wea. Forecasting, 22, 11571176.

Wu, C.-C., P.-H. Lin, S. D. Aberson, T.-C. Yeh, W.-P. Huang, J.-S. Hong, G.-C. Lu, K.-C. Hsu, I.-I. Lin, K.-H. Chou, P.-L. Lin, and C.-H. Liu, 2005: Dropwindsonde Observations for Typhoon Surveillance near the Taiwan Region (DOTSTAR): An overview. Bull. Amer. Met. Soc., 86, 787-790. 